\section{STFM OFFERS MEDICAL SCHOOL FACULTY FUNDAMENTALS CERTIFICATE PROGRAM}

It can be challenging to onboard new faculty and ensure they have the foundational skills and knowledge to be effective teachers. Faculty development is critical. Faculty with 5 years of experience or less identified these critical needs: teaching skills, developing scholarly activities, and career development. ${ }^{1}$

The Society of Teachers of Family Medicine (STFM) has launched the Medical School Faculty Fundamentals Certificate Program (MSFF), which provides distance learning in an online format, with interaction with a faculty instructor and real-life application of lessons.

"The Medical Student Faculty Fundamentals Course format allows faculty to access the information at their own pace and in the order that works best for them. If you're looking for ways to engage faculty new to medical student education or what to brush up yourself, take advantage of this opportunity," said Karly Pippitt, MD, MSFF faculty instructor. MSFF will cover fundamental topics such as the structure and requirements of medical student education; how to be an effective and efficient faculty member ${ }_{i}$ the nuts and bolts of curriculum development and teaching; and strategies for assessment, feedback, and remediation of students.

The MSFF Certificate Program's 14 self-led courses include readings, videos, interactive modules, quizzes, and assignments. Courses include:

- Curriculum Development

- Clinical Teaching Skills

- Classroom Teaching

- Assessment and Evaluation

- Scholarly Activity

- Giving Feedback

- Medical Students in Difficulty

- Writing for Publication

- Advising Medical Students

- Time Management

- Incorporating Students Into Your Clinical Workflow

- LCME and COCA Requirements

- Academic Structure and Professional Advancement

- Establishing Professional Boundaries

According to the best principles of instructional design, each course features clear, concise content ${ }_{i}$ frequent quizzing; video interviews with stories; and advice from experienced faculty; and some assignments that receive feedback from a faculty instructor. The assignments are carefully designed to help a new faculty member learn more about the resources available to them at their own institutions.

Developed by the STFM Medical School Education Committee, STFM staff, and subject matter experts, the MSFF Certificate Program is intended to be completed over the course of an entire year, and each participant will earn 35 hours of CME credits.

To graduate from this national certificate program, participants must complete all courses and assignments and pass a final exam.

Traci Brazelton, CAE

\section{References}

1. Danilkewich A, et al. Implementing an evidence-informed faculty development program. Can Fam Physician. 2012;58(6):e337-343.

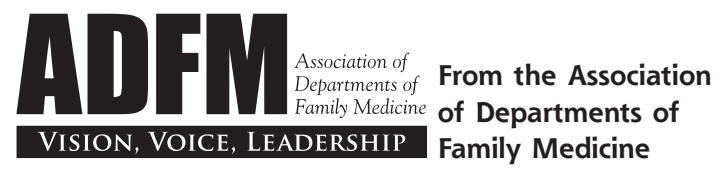

Ann Fam Med 2020;18:186-189. https://doi.org/10.1370/afm.2523.

\section{INTRODUCING THE BEST PRACTICE GUIDE FOR STRATEGIC PLANNING TO INCREASE STUDENT CHOICE OF FAMILY MEDICINE}

The family of Family Medicine has created several initiatives to increase student choice of Family Medicine over the years. The most recent is a set of strategies recommended by the Family Medicine for America's Health (FMAHealth) Workforce Education and Development Tactic Team ${ }^{1}$ which has become the current collective effort to increase student interest, America Needs More Family Doctors: $25 \times 2030 .{ }^{2}$ The FMAHealth Workforce Tactic Team initiated several projects related to these strategies, one of which evolved into a guide of evidence and best practices for Departments of Family Medicine (DFMs) in their piece of the puzzle to attract, retain, and train a diverse workforce of family physicians to address the growing population of the United States. ${ }^{3}$

The ADFM Education Transformation Committee, targeting ADFM's strategic priority to "increase the number of US medical school graduates selecting family medicine as a career," produced the "Best Practice Guide for Strategic Planning to Increase Student Choice of Family Medicine" as a supporting activity for the $25 \times 2030$ initiative. The goals of the Guide are to (1) pro- 